\title{
Experimental Reconfirmation of Tani's Theory about How an
}

\section{Atomizer Works}

\author{
Hirotsugu HATTORI* and Masatsugu YAMAGISHI \\ Department of Fine Materials Engineering, \\ Faculty of Textile Science and Technology, Shinshu University, \\ 15-1, Tokida 3,Ueda-shi, Nagano 386-8567, Japan
}

E-mail: hhatori@shinshu-u.ac.jp

Phone: 0268-21-5460

Fax: 0268-21-5321

Keywords: Atomizer, Bernoulli’s Theorem, Tani’s Theory, Dynamic Similarity, Flow in Curved Path

The reason why an atomizer works is frequently explained by applying Bernoulli's theorem to the air jet which forms behind an air release pipe. As early as 1948, Tani pointed out that applying Bernoulli's theorem to the air jet of an atomizer was not correct. He described that the pressure should be the atmospheric pressure at anywhere in the air jet. He explained that the reason an atomizer works consists in the fact that the suction pipe is partly located in the air jet. He carried out brief experiments. In spite of the existence of Tani's theory and his brief experiments, the mistaken explanation, in which Bernoulli's theorem is applied to the air jet, appears in many publications today.

In this study, air flow patterns were observed and pressure distribution was measured mainly by using a large-scale model whose shape is geometrically similar to that of a small prototype of the atomizer, under the condition of dynamic similarity. These experimental results reconfirmed Tani's theory about why an atomizer works.

Introduction

A traditional atomizer or sprayer consists of a combination of a horizontal small pipe A (air release pipe), a vertical small pipe $B$ (suction pipe) and a liquid container, as shown in Figure 1. Pipe B is placed perpendicular to pipe A in such a way that the top end of the pipe $B$ is almost touching the down-stream end of pipe A but is not entirely blocking it. The other end of pipe $B$ dips in the liquid in the container. When the air passes through pipe A and is released from the down-stream end at high velocity, the liquid in the container rises up into pipe B. The liquid, having reached the top end of pipe $B$, is broken into small drops and carried away by the stream of air.

The reason an atomizer works is frequently explained by means of Bernoulli's theorem, as follows. The stream of air that is released from the end of pipe A forms an air jet diverging in the direction of flow. If we apply Bernoulli's theorem between the points $\mathrm{C}$ and $\mathrm{D}$ in the air jet, the pressure at $\mathrm{C}$ is lower than the pressure at $\mathrm{D}$, because the velocity at $\mathrm{C}$ is greater than

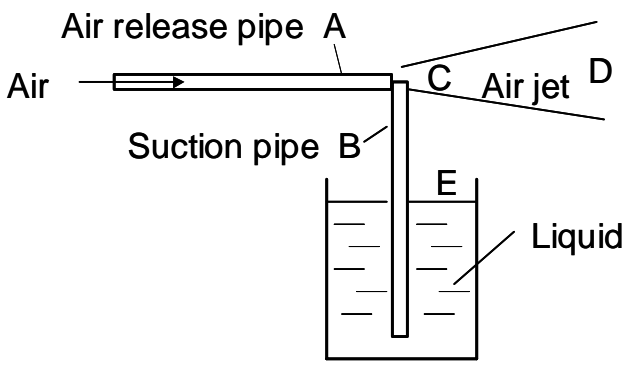

Fig.1 Traditional atomizer 
the velocity at $D$. The pressure at $D$ is the atmospheric pressure as well as the pressure acting on the liquid surface $\mathrm{E}$ in the container. The difference between the pressure acting on the liquid surface $\mathrm{E}$ and the pressure at point $C$ pushes the liquid up into pipe $B$.

As early as 1948, Tani pointed out that applying Bernoulli's theorem to the air jet of an atomizer, shown from the point $\mathrm{C}$ to $\mathrm{D}$ in Figure 1, was not correct (Tani, 1948). He described that the pressure should be the atmospheric pressure at anywhere in the air jet. He measured the pressure in the air jet using a hand-made static tube. He also explained that the reason an atomizer works consists in the fact that the suction pipe is partly located in the air jet. He added that the reason lies in the interaction between the air jet and the suction pipe.

Tani produced a stream of air using a bicycle pump and measured the number of strokes required to aspirate a certain amount of water, instead of directly measuring the pressure in the suction pipe. He changed the height of various-shaped suction pipes located just behind the down-stream end of the air release pipe.

In spite of the existence of Tani's theory and his brief experiments, the foregoing incorrect explanation,

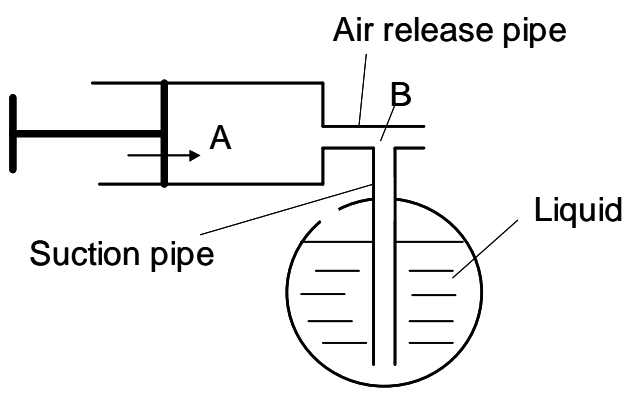

Fig.2 Example of an atomizer that does not work

in which Bernoulli's theorem is applied to the air jet of an atomizer, appears in many publications today. It is important for us to understand Tani's theory to design atomizers. If we make an atomizer such as one that is shown in Figure 2, for example, the atomizer would never work. In this type of atomizer, Bernoulli's equation is often applied to the points A and B shown in Figure 2. Clearly, the pressure at $B$ is lower than the pressure at A. However, the pressure is not lower than the atmospheric pressure anywhere in the air release pipe.
Bernoulli's theorem is one of the most important learning tasks in the field of science and technology. The application of the theorem should not be mistaken. As mentioned above, Tani pointed out that Bernoulli's theorem should not be applied to the air jet of the atomizer, from the point $\mathrm{C}$ to $\mathrm{D}$ in Figure 1. Meanwhile, he described that Bernoulli's theorem could be applied in the narrow range between the air release pipe and the suction pipe. However, from Tani's brief experiments, it is difficult to understand exactly how the air flows near the top of the suction pipe after it leaves the air release pipe. The purpose of this study is to reconfirm Tani's theory by investigating experimentally how the air flows, how the pressure in the suction pipe decreases and how the decreased pressure is balanced by the atmospheric pressure surrounding the atomizer.

\section{Experiments and Discussion}

\subsection{Pressure distribution in the air jet}

Pressure distribution in the air jet was measured using an atomizer as shown in Figure 3. The atomizer was cut by a vertical plane including the central axis of the air release pipe. The air release pipe and the suction

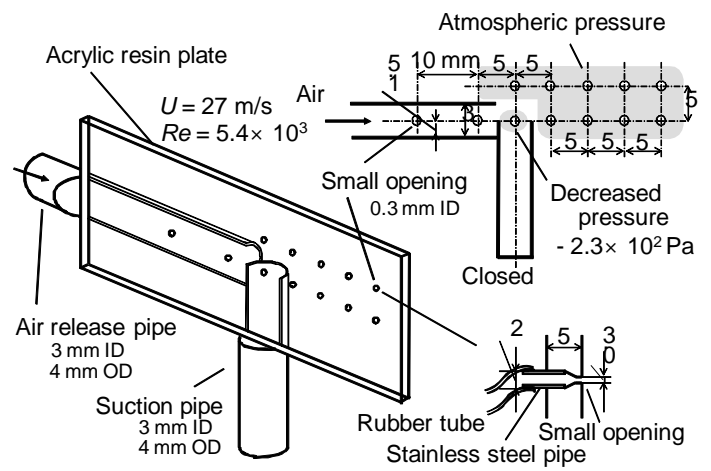

Fig.3 Apparatus for measuring the pressure in air jet and the experimental results

pipe were made of brass, with $3 \mathrm{~mm}$ inside diameter and $4 \mathrm{~mm}$ outside diameter. The top end of the suction pipe was located at the level of the central axis of the air release pipe. An acrylic resin plate was attached on the plane and small openings of $0.3 \mathrm{~mm}$ in diameter were arranged on the acrylic resin plate to measure the static pressure through them.

The results are also shown in Figure 3. In Figure 3, the average air velocity was $27 \mathrm{~m} / \mathrm{s}$. The pressure was 
the atmospheric pressure anywhere in the air jet, as proposed by Tani (1948). Only at the top end of the suction pipe, was decreased pressure measured. The gauge pressure, that is, the difference between the pressure measured and the atmospheric pressure was $-2.3 \times 10^{2} \mathrm{~Pa}$. In the air release pipe, the pressure was higher than the atmospheric pressure.

The atomizer shown in Figure 3 has a semicircular air release pipe and a suction pipe. In this type of atomizer, the presence of the acrylic resin plate caused less pressure reduction at the top of the suction pipe compared with the atomizer consisting of circular pipes. The atomizer consisting of circular pipes provided pressure reduction as great as $-4.4 \times 10^{2} \mathrm{~Pa}$. This value permits the atomizer to work successfully.

\subsection{Large-scaled atomizer model}

Usually an atomizer uses small pipes of 2 or $3 \mathrm{~mm}$ in diameter. It is difficult to study the airflow of the atomizer on such a small scale. So, a large-sized model was prepared. The large-sized model consisted of pipes of $20 \mathrm{~mm}$ inside diameter and $22 \mathrm{~mm}$ outside diameter. According to the dynamic similarity, if the Reynolds number of two geometrically similar flows is the same, the streamline pattern for one flow will be similar to that for the other flow.

\subsection{Pressure in the suction pipe}

As mentioned above, Tani (1948) did not measure the pressure in the suction pipe directly. However, his experiment suggested that the pressure in the suction pipe decreased depending on the relative height of the air release pipe and the suction pipe.

In this study, the pressure in the suction pipe was measured on the basis of the atmospheric pressure. The relative height of the air release pipe and the suction pipe was changed by moving the suction pipe up and

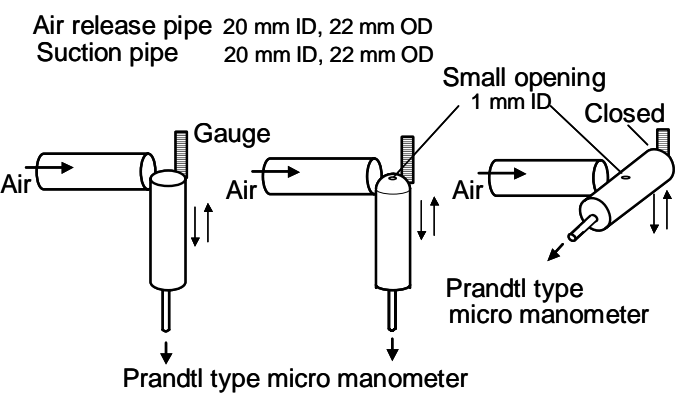

Suction pipe
(a) Vertical
(b) Vertical
(c) Horizontal
Ordinary cut
Hemispherical top

Fig.4 Atomizers with three kinds of suction pipes down. Three kinds of suction pipes, indicated by (a)-(c) in Figure 4, were used. These include an ordinary vertical pipe cut perpendicular to its central axis (a), a vertical pipe with a hemispherical top (b) and a horizontal pipe (c). Tani proposed that the horizontal suction pipe provided the same effect as the vertical pipe did. In order to measure the pressure, a small opening of $1 \mathrm{~mm}$ in diameter was made at the highest position of the hemispherical top in the case of (b), and in the upper surface of the horizontal pipe in the case of (c).

Figure 5 shows the relation between the pressure in the suction pipe and the relative height of the air release pipe and the suction pipe. In Figure 5, the

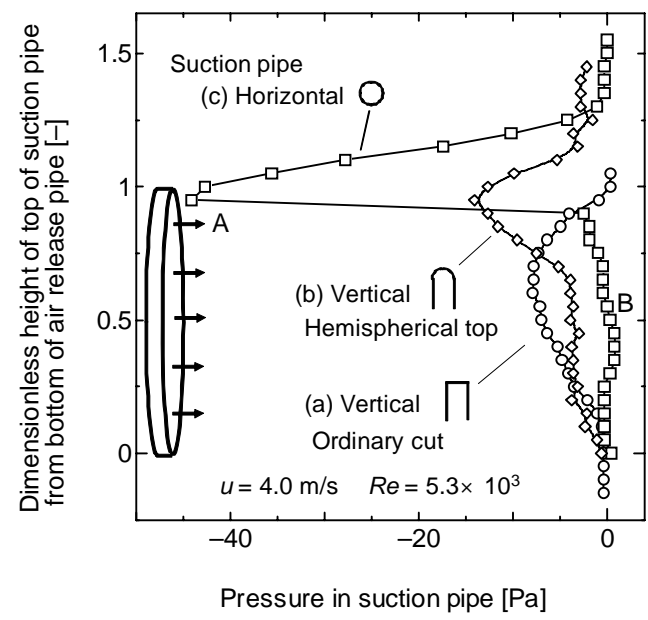

Fig.5 Relation between pressure in suction pipe and the relative height of air release pipe and suction pipe

average air velocity in the air release pipe was $4.0 \mathrm{~m} / \mathrm{s}$. This air velocity was chosen in such a way that the Reynolds number was the same as in the case of the small atomizer prototype shown in Figure 3, and that the dynamic similarity held between the small prototype and the large-sized model of atomizer. The Reynolds number was about $5.3 \times 10^{3}$, when the inside diameter of the air release pipe was chosen as a characteristic length and so was the average air velocity in that pipe as a characteristic velocity. In Figure 5, the pressure in the suction pipe decreased depending on the relative height of the air release pipe and the suction pipe, as suggested by Tani (1948). In the case of the ordinary vertical pipe (a), the pressure in the suction pipe decreased when the top end of the suction pipe was located in a relatively low position. Maximum pressure reduction in the horizontal suction pipe (c) 
was greater than those of the two other types.

According to dynamic similarity, the larger the scale of the atomizer, the smaller the pressure reduction. In Figure 5, the pressure reduction was about $40 \mathrm{~Pa}$ at most. So, a Prandtl type micro manometer was used to measure such a slight pressure reduction. Although the pressure reduction in the large-sized model is slight, the corresponding pressure reduction in the small-sized prototype atomizer must be as great as about $1.8 \times 10^{3}$ $\mathrm{Pa}$. This value can be calculated using the following equation

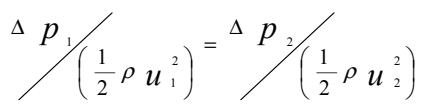

where, $\Delta p$ is the pressure reduction and $u$ is the average air velocity in the air release pipe. Subscript 1 means the small-sized prototype and 2 the large-sized model of the atomizer. $\rho$ is the density of the air.

\subsection{Air flow pattern around the top of suction pipe}

Using an atomizer of the same size as the one used to measure the pressure in the suction pipe, the air flow pattern was observed. For the observation, incense smoke was mixed with air in the air release pipe. When the pressure at the top of the horizontal suction pipe mostly showed a tendency to decrease (point A in Figure
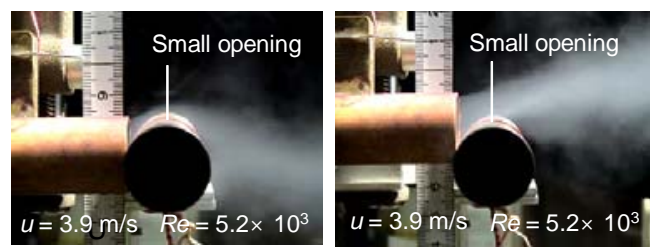

Air stream along the curved path (point A in Fig.5)

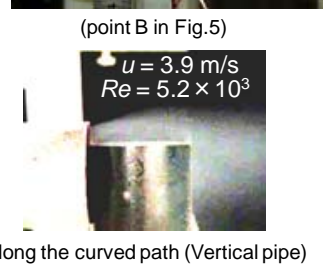

Air stream along the curved path (Vertical pipe)

Fig.6 Air flow pattern around the top of the suction pipe

5), it was observed that the air flowed in a curved path along the upper surface of the suction pipe, as shown in the upper left of Figure 6. On the contrary, when the pressure did not decrease (point B in Figure 5), such a curved flow pattern was not observed. In this case, the air flowed obliquely upward out of the air release pipe, as shown in the upper right of Figure 6. A curved flow pattern was observed also in cases of the ordinary vertical suction pipe and the vertical suction pipe with hemispherical top. The curved flow pattern around the top end of the ordinary vertical suction pipe was shown in the right bottom of Figure 6.

As is well known, when the fluid flows in curved lines, a pressure difference must exist in a transverse direction of the flow. The pressure rises from the concave side to the convex side (Prandtl, 1952). In this way, in the case of the atomizer, decreased pressure on the concave side must be balanced by the atmospheric pressure on the convex side of the stream.

\subsection{Pressure distribution around the top of the suction pipe}

Pressure distribution around the top of the suction pipe was measured using the large-sized model of the atomizer. Again, the above-mentioned three kinds of

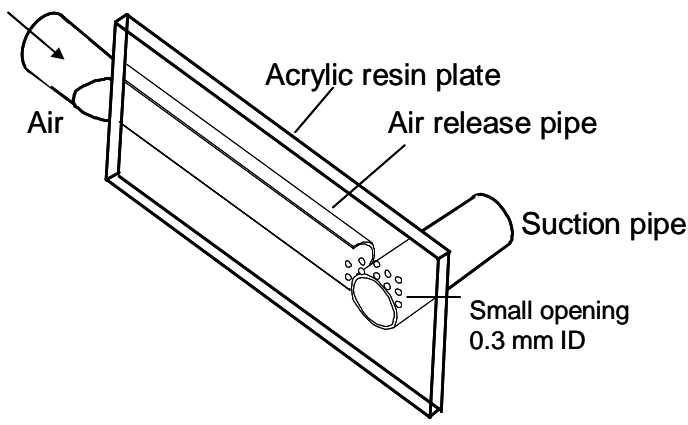

Fig.7 Apparatus for measuring the pressure distribution around the top of suction pipe

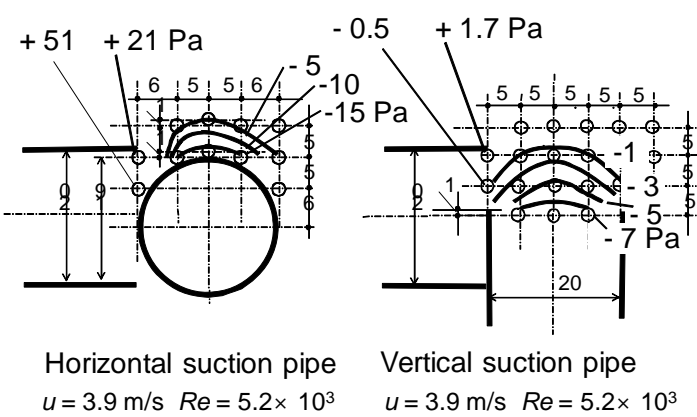

Fig.8 Pressure measuring points and pressure distribution around the top of suction pipe

suction pipes were used. Figure 7 shows the atomizer having a horizontal suction pipe. The atomizer was cut in a vertical plane in a similar manner as mentioned above. Figure 8 shows the pressure measuring points on the vertical plate and the pressure distribution in the cases of the horizontal suction pipe and ordinary vertical suction pipe. The pressure distribution is 
illustrated by contour curves. In both cases, the shape of the contour curves were similar to that of the air flow pattern shown in the upper left of Figure 6. From these results, it was confirmed how the decreased pressure at the top of the suction pipe was balanced by the surrounding atmospheric pressure.

It is not so difficult to understand why the pressure at the top of the suction pipe decreases. The left-hand side of Figure 9 illustrates a fluid flow around a sphere or a circular cylinder placed perpendicular to the flow direction. The boundary layer separates near the shoulder of the sphere or the cylinder. The pressure is also at its minimum near the shoulder. The minimum is lower than the static pressure. Pressure distribution along the surface of the sphere or the cylinder has usually been explained by applying Bernoulli's theorem to the points 1 and 2 along a streamline shown on the left-hand side of Figure 9 (Shapiro, 1961). The right-hand side of Figure 9 illustrates a fluid flow around the top of the horizontal suction pipe of the atomizer. Also in the case of the atomizer, Bernoulli's theorem can be applied between the points 1 and 2 on the right-hand side of Figure 9. The pressure at the point 1 is higher than the atmospheric pressure and the Two points to which Bernoulli's

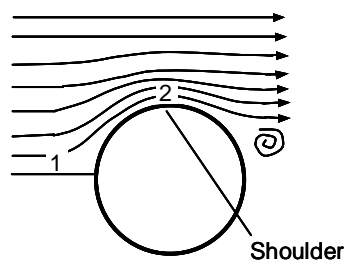

Fluid flow around the sphere or cylinder

Fluid flow around the top of horizontal suction pipe of atomizer
Fig.9 Air flow pattern around the sphere or cylinder and the top of horizontal suction pipe

pressure at the point 2 is lower than the atmospheric pressure, as can be seen from the left-hand side of Figure 8. Tani (1948) also indicated that Bernoulli's theorem could be applied in the narrow range between the air release pipe and the suction pipe.

\subsection{Pressure in small pipes located in the air stream}

Small stainless steel pipes of $1.6 \mathrm{~mm}$ inside diameter and $2 \mathrm{~mm}$ outside diameter were protruded into the air stream in a circular acrylic resin pipe of 41 $\mathrm{mm}$ inside diameter, as shown in Figures 10(a) and (b). The small pipe shown in Figure 10(a) is an ordinary

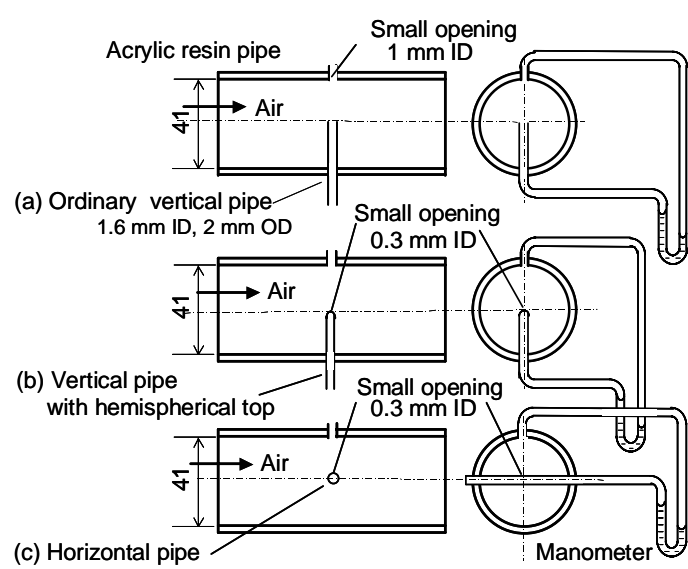

Fig.10 Small pipes located in the air stream

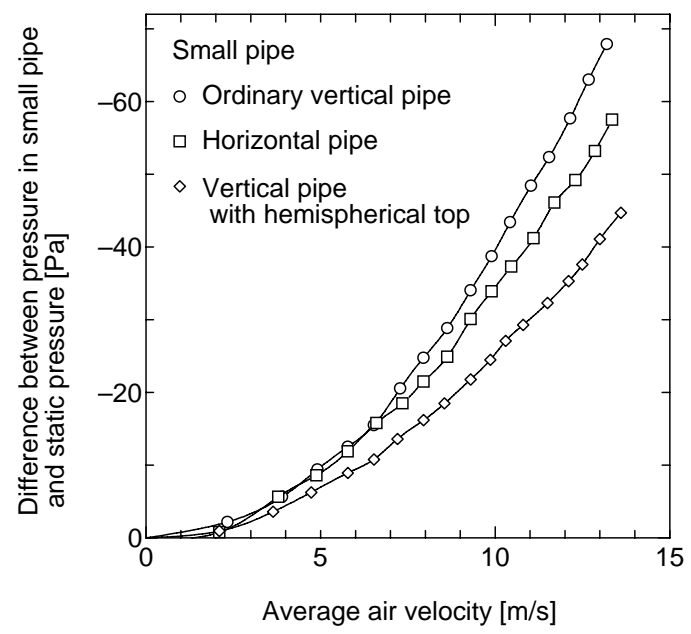

Fig.11 Pressure in small pipes located in the stream of air pipe cut perpendicular to its central axis. The small pipe shown in Figure 10(b) has a hemispherical tip. At the top of the hemisphere, a small opening of $0.3 \mathrm{~mm}$ in diameter was made for pressure measurement. Furthermore, the same small pipe was located horizontally and perpendicular to the flow direction, as shown in Figure 10(c). The horizontal small pipe penetrated completely through the wall of the $41 \mathrm{~mm}$ pipe. It crossed over the central axis of the $41 \mathrm{~mm}$ pipe. The small opening of $0.3 \mathrm{~mm}$ in diameter was located at the upper shoulder of the horizontal pipe. The pressure of each small pipe was measured on the basis of the static pressure. The static pressure was measured through the small opening of $1 \mathrm{~mm}$ in diameter located at the wall of the $41 \mathrm{~mm}$ pipe.

The results were shown in Figure 11 indicating that the pressure in each small pipe was more or less lower than the static pressure. From these results, it is 
clear that if a small pipe is located in the air stream in a manner as shown in Figure 10, the pressure in the small pipe decreases. This is why the atomizer works.

\section{Conclusions}

Pressure was measured in the air jet of an atomizer. The pressure was the atmospheric pressure anywhere in the air jet, as proposed by Tani (1948). Pressure in the suction pipe was measured using a large-scaled model whose shape is geometrically similar to that of the small prototype of the atomizer, under the condition of dynamic similarity. Pressure in the suction pipe decreased depending on the relative height of the air release pipe and the suction pipe, similarly to Tani's experiment. In the case when the pressure decreased, an air stream along a curved path was observed at the top of the suction pipe. Because of this curved air stream, decreased pressure on the concave side of the stream could be balanced by the atmospheric pressure on the convex side. Contour curves confirmed such a pressure balance. Bernoulli's equation should not be applied to the air jet but only to the narrow space between the air release pipe and the suction pipe, as suggested by Tani (1948).

In this study, we discussed only the two-dimensional flow along the vertical plane including the central axis of the air release pipe. However, the actual air flow of the atomizer is certainly a more complicated three-dimensional flow.

\section{Nomenclature}

$u=$ average air velocity $[\mathrm{m} / \mathrm{s}]$

$\Delta p=$ pressure reduction from the atmospheric pressure $\quad[\mathrm{Pa}]$

$\rho=$ density of the air

$\left[\mathrm{kg} / \mathrm{m}^{3}\right]$

$<$ Subscript $>$

$1=$ small-sized prototype of the atomizer

$2=$ large-sized model of the atomizer

\section{Literature Cited}

Prandtl, L.; Essentials of Fluid Dynamics, p. 47, Blackie and Son, London and Glasgow, U.K. (1952)

Shapiro, A. H.; Shape and Flow - The Fluid Dynamics of Drag -, p. 138, Doubleday and Company, Garden City,
U.S.A. (1961)

Tani, I.; "Principle of the Atomizer,"(in Japanese) Kagaku Asahi, 2, 22-23, (1948) 